Article

\title{
Performance Improvement of GaN Based Laser Diode Using Pd/Ni/Au Metallization Ohmic Contact
}

\author{
Wenjie Wang ${ }^{1,2}, *$, Wuze Xie ${ }^{1,2}$, Zejia Deng ${ }^{1,2}$, Haojun Yang ${ }^{1,2}$, Mingle Liao ${ }^{1,2}$, Junze Li ${ }^{1,2}$, \\ Xiaojia Luo ${ }^{1,2}$, Song Sun ${ }^{1,2, *}$ and Degang Zhao ${ }^{3,4}$ \\ 1 Microsystem \& Terahertz Research Center, China Academy of Engineering Physics, Chengdu 610200, China; \\ xiewuze@mtrc.ac.cn (W.X.); dengzejia@mtrc.ac.cn (Z.D.); yanghaojun@mtrc.ac.cn (H.Y.); \\ liaomingle@mtrc.ac.cn (M.L.); lijunze@mtrc.ac.cn (J.L.); luoxiaojia@mtrc.ac.cn (X.L.) \\ 2 Institute of Electronic Engineering, China Academy of Engineering Physics, Mianyang 621999, China \\ 3 State Key Laboratory of Integrated Optoelectronics, Institute of Semiconductors, Chinese Academy of \\ Science, Beijing 100083, China; dgzhao@red.semi.ac.cn \\ 4 Center of Materials Science and Optoelectronics Engineering, University of Chinese Academy of Sciences, \\ Beijing 100049, China \\ * Correspondence: wangwenjie@163.com or wangwenjie@mtrc.ac.cn (W.W.); sunsong@mtrc.ac.cn (S.S.); \\ Tel.: +86-28-6572-6091 (W.W.); +86-28-6572-6090 (S.S.)
}

Received: 30 March 2019; Accepted: 25 April 2019; Published: 28 April 2019

\begin{abstract}
We report an investigation of the effects of different metal systems and surface treatment on the contact performance of $\mathrm{GaN}$ lasers. We found that multi-element metal alloy and surface chemical treatment are the keys to achieve good ohmic behavior contacts on $\mathrm{GaN}$ laser diodes. $\mathrm{Pd} / \mathrm{Ni} / \mathrm{Au}$ contact demonstrates excellent thermal stability and lowest specific contact resistivity in these metal systems. Properly adjusting the thickness of the Pd and Ni layer and pretreating with the $\mathrm{KOH}$ solution can further improve the ohmic contact performance. The improved ohmic behavior of the $\mathrm{KOH}$ solution pretreated $\mathrm{Pd} / \mathrm{Ni} / \mathrm{Au}$ contact is attributed to removing surface oxides and the reduction of the schottky barrier heights due to the metal Pd has a high work function and the interfacial reactions occurring between the $\mathrm{Pd}, \mathrm{Ni}, \mathrm{Au}$, and $\mathrm{GaN}$ extends into the $\mathrm{GaN}$ film. As a result, a low contact resistivity of $1.66 \times 10^{-5} \Omega \cdot \mathrm{cm}^{2}$ can be achieved from $\operatorname{Pd}(10 \mathrm{~nm}) / \mathrm{Ni}(10 \mathrm{~nm}) / \mathrm{Au}(30 \mathrm{~nm})$ contacts with $\mathrm{KOH}$ solution pretreated on top of the laser diode structure. The power of the $\mathrm{GaN}$ based laser diode with the $\mathrm{Pd} / \mathrm{Ni} / \mathrm{Au}$ metallization ohmic contact can be enhanced by 1.95 times and the threshold current decreased by $37 \%$ compared to that of the conventional ohmic contact $\mathrm{Ni} / \mathrm{Au}$.
\end{abstract}

Keywords: GaN; laser diode; ohmic contact; PVD deposition; alloys; $\mathrm{Pd} / \mathrm{Ni} / \mathrm{Au}$

\section{Introduction}

Gallium nitride (GaN) based opto-electronic devices such as laser diodes [1-3], light emitting diodes [4-7], power devices [8,9], and violet photodetectors [10-12], among others, have received considerable attention in the last decade. Particularly in recent years, GaN-based lasers have been widely used in the fields of bio-chemical analysis, full-color displays, laser processing, high-density storage, laser pumping, and laser lithography. In order to meet the requirements of these broad applications, GaN-based lasers require higher output power, lower resistance, and better thermal stability. There are many factors that could affect the performances of the laser devices such as material quality, ohmic contact, cleavage, facet coating, etc. Among these factors, ohmic contact is arguably the most important one. Since the laser diode usually operates at a large current density, p-type ohmic contact is critical for reducing the operating voltage. Otherwise, the device would heat up severely under high current injection, which is detrimental to the device lifetime and reliability, and it 
is impossible to obtain high output power. Therefore, the development of low-resistance and stable p-type GaN ohmic contacts is consistently pursued over the world.

It is a grand challenge for researchers to fabricate a low-resistance $\mathrm{p}-\mathrm{GaN}$ ohmic contact which is mainly determined by the intrinsic quality of the $\mathrm{p}-\mathrm{GaN}$ material and the ohmic metallization process. Regarding the material quality, it is generally difficult to grow heavily doped $\mathrm{p}-\mathrm{GaN}$ materials. At present, the typical carrier density can only reach $\sim 10^{17} \mathrm{~cm}^{-3}$ [13] or even lower, which is not sufficient for the laser diode device. An alternative solution to obtain a low-resistance ohmic contact, which is perhaps more viable from the perspective of device engineering, is to improve the ohmic contact processing, which depends on three major parameters: the material composition of the metal contact, the thickness of the contact film, and the condition of the metallization process. For the material composition, the resistivity of the ohmic contact depends on the work function of the metal. Since $\mathrm{GaN}$ has a large band gap of $3.4 \mathrm{eV}$ and a high electron affinity of $4.1 \mathrm{eV}$, the potential barrier of the metal contact on the $\mathrm{p}-\mathrm{GaN}$ material can reach as high as $7.5 \mathrm{eV}$ [14]. To obtain a low-resistance ohmic contact, the schottky barrier height of the metal and semiconductor interfaces should be small. Unfortunately, there is currently no metal material available with a work function that is high enough to overcome such a high potential barrier. Tunneling through the potential barrier is mainly responsible for the formation of ohmic contacts on p-GaN in most metallization schemes.

Currently, the $I-V$ characteristics similar to ohmic properties can be obtained using different process conditions, but the contact resistivity is usually $10^{-2}$ to $10^{-3} \Omega \cdot \mathrm{cm}^{2}[15,16]$. Such a resistance does not pose a serious problem for a light-emitting diode (LED) for general display, whereas it is much more severe for a laser diode device because the high operating current density of laser diode causes problems such as defect generation, degradation, or inter-diffusion. The laser diode that achieves a low threshold current requires that the contact resistivity must be less than $10^{-4} \Omega \cdot \mathrm{cm}^{2}$, which is still difficult to achieve at the present stage. A versatile and excellent ohmic contact is of great significance for improving the performance and industrialization of GaN lasers. Many researchers have made efforts in different ohmic metal systems, surface chemical treatment, etc., to obtain better resistivity. A commonly adopted method is to use a metal with a high work function as the pelectrode. Metals with a high work function are chosen to achieve low resistance on $\mathrm{p}-\mathrm{GaN}$, such as Ni/Au [17-19], Ti/Pt/Au [20], $\mathrm{Pd} / \mathrm{Au}$ [21,22], $\mathrm{Pt} / \mathrm{Ru}$ [23], $\mathrm{Pd} / \mathrm{Pt} / \mathrm{Au}$ [24,25], Ni/Pd/Au [26]. Among these metal systems, ohmic contact metals based on Ni [17-19,26,27] and Pd [21,22,24-26,28,29] are the most popular candidates for the p-type ohmic electrodes because they have better contact resistances and are compatible with the device etching processes.

Despite these breakthroughs, previous studies have only focused on one or two metals, or the p-GaN single-layer; none of them have systematically studied the effects of various ohmic metal systems and surface treatments on the performance of the same GaN lasers. In particular, few articles have reported on p-type ohmic contact schemes that have large process windows for low specific contact resistivity in GaN laser diode fabrication. For this purpose, it is particularly necessary to compare the effects of different metal systems and surface treatment on the contact performance of GaN lasers. In addition, the p-GaN surface is active and easily oxidized. As mentioned in reference [30], there is a $\sim 2$ nm thick amorphous "contaminated layer" on the surface of the GaN which consists of gallium oxide and adsorbed carbon or hydrocarbon. The "contaminated layer" increases the extra barrier height and hinders the transport of carriers from metal to semiconductor. References [30,31] demonstrate the presence of the surface oxide layer using Transmission Electron Microscope (TEM) and X-ray Photoelectron Spectroscopy (XPS). Therefore, a surface treatment is usually required before the contact is prepared. The chemical pretreatment generally uses $\mathrm{HCl}$ solution [32], and also uses $\mathrm{HF}$ [33], aqua regia [21], $\mathrm{KOH}[31,34-36]$, and $(\mathrm{NH} 4)_{2} \mathrm{~S}_{x}$ [37] solutions. The contact resistivity before and after treatment is not significant changed, and the effect is not obvious. The reason may be that the oxide layer is not completely removed, there is surface damage caused by corrosion, and the surface is re-oxidized. Finding an effective chemical solution to pretreat before metal deposition can result in a further lower ohmic contact. 
In this study, we perform four series of ohmic contact metal experiments by varying the composition of metal alloys, changing metal thickness, and adding chemical pretreatment to systematically investigate the effect of different metal systems on the ohmic contact of GaN lasers and to widen a processing window for forming the best electrical property of the ohmic metal system. Current-voltage characteristics $(I-V)$ of the contacts are measured using a semiconductor parameter analyzer at room temperature. A tungsten filament Scanning Electron Microscope (SEM) JEOL-6390 (JEOL, Tokyo, Japan) with an attached EDX Unit (Energy Dispersive X-ray Analyses) and combined Raith EBL \& SEM system with high magnification range accelerating voltage $20,10 \mathrm{kV}$, respectively, is used to investigate the thin films microstructure. An Oxford Instruments (Abingdon, UK) MFP-3D Atomic Force Microscope (AFM) is used to measure the surface topography of the deposited p electrode metal alloy thin films after annealing. From this, ohmic contact formation mechanism of a wide variety of metal schemes formed on p-type GaN will be discussed.

\section{Experiments}

GaN based laser diode samples used in this study are grown epitaxially on c-oriented GaN homogeneous substrates by metal organic chemical vapor deposition (MOCVD). The epitaxial process of GaN laser diode adopts our existing standard process. Trimethylgallium (TMGa), Trimethylindium (TMIn), trimethylaluminum (TMAl), and ammonia $\left(\mathrm{NH}_{3}\right)$ are used as the source materials for $\mathrm{Ga}$, $\mathrm{In}, \mathrm{Al}$, and $\mathrm{N}$, respectively. The n-type and p-type doping precursors are silane $\left(\mathrm{SiH}_{4}\right)$ and dicyclopentadienyl magnesium $\left(\mathrm{Cp}_{2} \mathrm{Mg}\right)$, respectively. For detailed epitaxial growth processes, please refer to reference [38]. The common epitaxial structure of the GaN based laser diode is shown in Figure 1, which consists of a $2 \mu \mathrm{m}$ thick GaN buffer layer, a $1 \mu \mathrm{m}$ thick n-AlGaN confinement layer, a $100 \mathrm{~nm}$ GaN lower waveguide layer, two pairs of InGaN/GaN quantum well structures as the active region, a $100 \mathrm{~nm}$ p-GaN upper waveguide layer, a $20 \mathrm{~nm}$ p-AlGaN electron blocking layer, a $600 \mathrm{~nm}$ thick p-AlGaN confinement layer, and a $80 \mathrm{~nm}$ thick $\mathrm{p}-\mathrm{GaN}$ contact layer with $\mathrm{Mg}$ concentration of $1 \times 10^{19} \mathrm{~cm}^{-3}$. After activating the $\mathrm{Mg}$ doped $\mathrm{p}-\mathrm{GaN}$ epilayer, the intermediate carrier concentration is measured to be $2 \times 10^{17} \mathrm{~cm}^{-3}$. Note that the $\mathrm{p}-\mathrm{GaN}$ carrier concentration of the top of the laser structure is in the order of $10^{17} \mathrm{~cm}^{-3}$ in general. It was used as a sample to systematically study the formation of low-resistance ohmic contacts, and the conclusions obtained are more versatile. GaN based laser diode samples are ultrasonically cleaned in acetone and isopropanol for $10 \mathrm{~min}$ twice and rinsed in deionized water before the experiments.

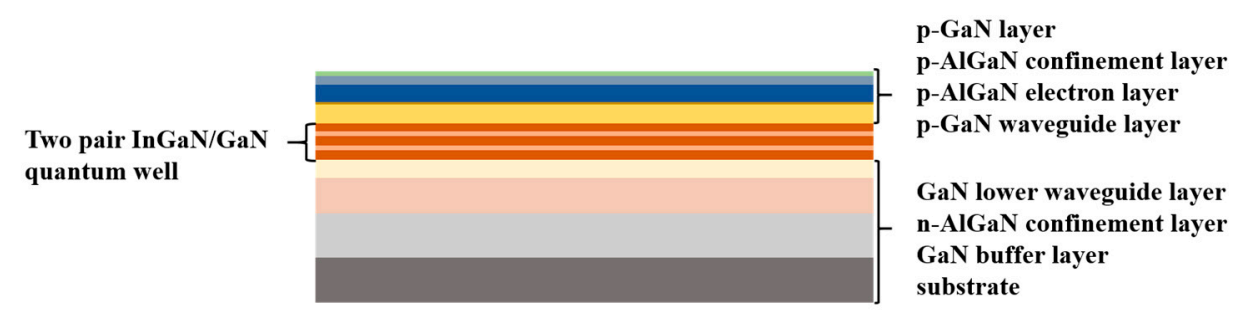

Figure 1. Schematic of $\mathrm{GaN}$ based laser diode structure.

\subsection{Thin $p$ Electrode Metal Films Fabrication}

The Ni/Au alloy system is the most ohmic contact material used by p-GaN. There are plenty of reports using $\mathrm{Ni} / \mathrm{Au}$ metallization annealed in $\mathrm{O}_{2}$ ambient to attain low resistance on $\mathrm{p}-\mathrm{GaN}$. Pt is the metal with the largest work function $(5.65 \mathrm{eV})$, so the study of ohmic contact related to Pt has received more attention. Ag has been widely used and investigated as an ohmic contact for flip-chip devices. Pd-based contacts are attractive for ohmic contact at low annealing temperature, and have been found to exhibit low contact resistance [24]. Few people use Pd metal in the GaN laser manufacturing process, since Pd-based contacts currently suffer from the repetitive difficulty and poor adhesion. However, their unrivalled advantages such as good repeatability and electrical properties are essential for reducing resistance and improving GaN laser performance. Based on the above reasons, we chose 
metals such as $\mathrm{Ni}, \mathrm{Au}, \mathrm{Ag}, \mathrm{Pd}$, and $\mathrm{Pt}$ as the main $\mathrm{p}-\mathrm{GaN}$ ohmic contact metal to study the effect of different metal systems on the ohmic contact performance of GaN lasers. The structures of electrode films are shown in Table 1 in detail.

Table 1. The detail of $\mathrm{p}$ electrode metal alloy films growth parameter and annealing condition.

\begin{tabular}{|c|c|c|c|}
\hline Film Structure & Growth Rate & Annealing Temperature & Annealing Ambient \\
\hline $\begin{array}{l}\mathrm{Ni} / \mathrm{Au}=10 / 30 \mathrm{~nm} \\
\mathrm{Ni} / \mathrm{Au}=15 / 15 \mathrm{~nm} \\
\mathrm{Ni} / \mathrm{Au}=15 / 30 \mathrm{~nm} \\
\mathrm{Ni} / \mathrm{Au}=15 / 50 \mathrm{~nm}\end{array}$ & $\begin{array}{l}\mathrm{Ni}=0.1 \mathrm{~nm} / \mathrm{s} \\
\mathrm{Au}=0.2 \mathrm{~nm} / \mathrm{s}\end{array}$ & $520^{\circ} \mathrm{C}$ & $\mathrm{N}_{2}: \mathrm{O}_{2}=4: 1$ \\
\hline $\mathrm{Ni} / \mathrm{Ag} / \mathrm{Zn}=5 / 120 / 30 \mathrm{~nm}$ & $\begin{array}{l}\mathrm{Ni}=0.1 \mathrm{~nm} / \mathrm{s} \\
\mathrm{Ag}=0.3 \mathrm{~nm} / \mathrm{s} \\
\mathrm{Zn}=0.2 \mathrm{~nm} / \mathrm{s}\end{array}$ & $500^{\circ} \mathrm{C}$ & $\mathrm{N}_{2}: \mathrm{O}_{2}=4: 1$ \\
\hline $\mathrm{Ni} / \mathrm{Ru} / \mathrm{Ag} / \mathrm{Au}=5 / 5 / 120 / 50 \mathrm{~nm}$ & $\begin{array}{l}\mathrm{Ni}=0.1 \mathrm{~nm} / \mathrm{s} \\
\mathrm{Ru}=0.1 \mathrm{~nm} / \mathrm{s} \\
\mathrm{Ag}=0.3 \mathrm{~nm} / \mathrm{s} \\
\mathrm{Au}=0.2 \mathrm{~nm} / \mathrm{s}\end{array}$ & $520^{\circ} \mathrm{C}$ & $\mathrm{N}_{2}: \mathrm{O}_{2}=4: 1$ \\
\hline $\mathrm{Pd} / \mathrm{Ni} / \mathrm{Au}=10 / 10 / 30 \mathrm{~nm}$ & $\begin{aligned} \mathrm{Pd} & =0.1 \mathrm{~nm} / \mathrm{s} \\
\mathrm{Ni} & =0.1 \mathrm{~nm} / \mathrm{s} \\
\mathrm{Au} & =0.2 \mathrm{~nm} / \mathrm{s}\end{aligned}$ & $520^{\circ} \mathrm{C}$ & $\mathrm{N}_{2}: \mathrm{O}_{2}=4: 1$ \\
\hline $\mathrm{Pd} / \mathrm{Pt} / \mathrm{Au}=10 / 30 / 50 \mathrm{~nm}$ & $\begin{aligned} \mathrm{Pd} & =0.1 \mathrm{~nm} / \mathrm{s} \\
\mathrm{Pt} & =0.1 \mathrm{~nm} / \mathrm{s} \\
\mathrm{Au} & =0.2 \mathrm{~nm} / \mathrm{s}\end{aligned}$ & $520^{\circ} \mathrm{C}$ & $\mathrm{N}_{2}$ \\
\hline
\end{tabular}

The $\mathrm{p}$ electrode metal alloy films are deposited on the photoresist patterned GaN laser diode samples by the high vacuum electron beam evaporation system Ei-5z (ULVAC, Chigasaki, Japan) under a pressure of $5 \times 10^{-6} \mathrm{~Pa}$ at a frequency of $5 \mathrm{MHz}$ and the maximum output power of $8 \mathrm{~kW}$. One hundred and eighty two-inch samples, or eight four-inch samples, or eight six-inch samples can be evaporated at one time, and the down-size is compatible, and the film non-uniformity is $\leq \pm 5 \%$. In order to form a well-defined multilayer metal structure and reduce the effect of the uniformity of the metal film on the contact resistance, the metal evaporation rate is controlled at a very small level $(0.1-0.3 \mathrm{~nm} / \mathrm{s})$ and high vacuum $\left(<10^{-5} \mathrm{~Pa}\right)$ by adjusting the evaporation time, the electron gun evaporation power, the carrier rotation rate, and other parameters of the evaporation coating system. The evaporation rates of gold, zinc, silver, and other metals are $0.2,0.2,0.3$, and $0.1 \mathrm{~nm} / \mathrm{s}$, respectively. A low-evaporation rate can be used to form a metal film having a uniform surface and a surface roughness of less than $0.5 \mathrm{~nm}$. At the same time, a uniform metal film is more advantageous for forming a perfect ridge shape in a subsequent etching process.

Pure metal evaporation particles (99.999\%) including palladium, nickel, gold, platinum, ruthenium, silver, titanium, and zinc with size $\left(<1 \times 0.5 \mathrm{~cm}^{2}\right)$ are loaded in the crucible used for the coating of all thin $\mathrm{p}$ electrode metal films in a high vacuum environment. The GaN based laser diode samples had dimensions $1.2 \times 1.2 \mathrm{~cm}^{2}$. A batch of GaN based laser diode samples are fixed on the substrates by a copper pin and then introduced into the chamber for each run. All substrates are cleaned in acetone and isopropanol, followed by nitrogen drying. The cleaned and dried substrates are fixed in the coating chamber with $10 \mathrm{rpm}$ rotation velocity. During the deposition, the chamber is pumped down to $10^{-5} \mathrm{~Pa}$ (the base pressure). The distance between the crucible and the baffle is $3 \mathrm{~cm}$, and the distance between the crucible and the substrate is equal to $50 \mathrm{~cm}$. The electron gun heats the metal particles so that it melts after melting, and the baffle blocks the pre-evaporation for two minutes. After the pre-evaporation is completed, the baffle is opened, and the crystal plate begins to record the thickness of the metal layer. During the coating process, the chamber temperature reached $65^{\circ} \mathrm{C}$ is recorded on a digital screen. When the thickness of the metal layer reaches the set thickness, the baffle is closed, the power of the electron gun is gradually reduced, and the system starts to cool down. 


\subsection{Annealing of $p$ Electrode Metal Thin Films}

The p electrode films deposited on GaN laser diode in this work are then lifted off in acetone. Metals that are not alloyed typically exhibit rectifying properties in contact with GaN, so the deposited material must be thermally annealed to form an ohmic contact. The contact of metal with p-type GaN is generally treated by rapid thermal annealing (RTA). In this work, the samples are rapid thermal annealed by RTA-500 rapid thermal processor at temperatures $500-520{ }^{\circ} \mathrm{C}$ for 5 min under $\mathrm{O}_{2}$ and $\mathrm{N}_{2}$ or only $\mathrm{N}_{2}$ ambient to form ohmic contact based on past experimental experience.

\section{3. $p$ Electrode Metal Thin Films Characterization}

Four different series of contact resistances were measured in this study: (i) The transport properties of varies metal alloy annealed $\mathrm{Ni}(10 \mathrm{~nm}) / \mathrm{Au}(30 \mathrm{~nm}), \mathrm{Ni}(5 \mathrm{~nm}) / \mathrm{Ag}(5 \mathrm{~nm}) / \mathrm{Zn}(30 \mathrm{~nm})$, $\mathrm{Ni}(5 \mathrm{~nm}) / \mathrm{Ru}(5 \mathrm{~nm}) / \mathrm{Ag}(120 \mathrm{~nm}) / \mathrm{Au}(50 \mathrm{~nm}), \operatorname{Pd}(10 \mathrm{~nm}) / \mathrm{Ni}(10 \mathrm{~nm}) / \mathrm{Au}(30 \mathrm{~nm})$, and $\operatorname{Pd}(10$ $\mathrm{nm}) / \mathrm{Pt}(30 \mathrm{~nm}) / \mathrm{Au}(50 \mathrm{~nm})$ contacts were compared as a function of multi-element metal alloy; (ii) those of $\mathrm{Pd}(10 \mathrm{~nm}) / \mathrm{Ni}(5 \mathrm{~nm}) / \mathrm{Au}(30 \mathrm{~nm}), \mathrm{Pd}(10 \mathrm{~nm}) / \mathrm{Ni}(10 \mathrm{~nm}) / \mathrm{Au}(30 \mathrm{~nm}), \operatorname{Pd}(10 \mathrm{~nm}) / \mathrm{Ni}(15 \mathrm{~nm}) / \mathrm{Au}(30 \mathrm{~nm})$, and $\mathrm{Pd}(10 \mathrm{~nm}) / \mathrm{Ni}(20 \mathrm{~nm}) / \mathrm{Au}(30 \mathrm{~nm})$ contacts, all annealed in oxygen at $520{ }^{\circ} \mathrm{C}$, were carried out and compared; and (iii) the performance of $\mathrm{Ni}(10 \mathrm{~nm}) / \mathrm{Au}(30 \mathrm{~nm})$ with different thickness $\mathrm{Pd}$ interlayer contacts, were measured and comparative analyzed; and (iv) the characteristics of $\mathrm{Pd}(10 \mathrm{~nm}) / \mathrm{Ni}(10 \mathrm{~nm}) / \mathrm{Au}(30 \mathrm{~nm})$, deposited on chemically treated $\mathrm{p}-\mathrm{GaN}$ contact layer surfaces and subsequently annealed in a mixture of nitrogen and oxygen ambient at $520{ }^{\circ} \mathrm{C}$, are assessed and compared to that of contacts formed by metallization on a $\mathrm{p}-\mathrm{GaN}$ contact layer surface rinsed in acetone and isopropanol only. The chemical pretreatments of $\mathrm{GaN}$ based laser diode samples are dip in $\mathrm{KOH}$ solution for $5 \mathrm{~min}$ and blown dry in $\mathrm{N}_{2}$ before metal evaporation process.

Calculated values of the specific contact resistivity were obtained by circular transmission line measurements (c-TLM) $[39,40]$. To determine the contact resistance, the voltage drop is measured by forcing a constant current through adjacent pads between the inner circle and the adjacent field of circular geometry. In order to avoid current flow at the contact edges in the circular contacts, a mesa structure is formed which defines a semiconductor region for the c-TLM pattern. The circular transmission line (c-TLM) pads are patterned on the p-type GaN contact layer by a standard photolithography technique. The schematic and optical image of the c-TLM patterns are shown in Figure 2. The inner circle radius is fixed $100 \mu \mathrm{m}$ and the spacing between the inner and the outer radii are varied from 20 to $55 \mu \mathrm{m}$ with a step of $5 \mu \mathrm{m}$. A contact structure with concentric rings is added to the gap to test the consistency of the c-TLM data.

For the c-TLM, the square resistance between the inner circle and outer radii is supposed to be equal. The total resistance $R_{\mathrm{t}}$ between two contacts is given by Equations (1) and (2):

$$
\begin{gathered}
R_{\mathrm{t}}=\frac{R_{\mathrm{sh}}}{2 \pi} \times\left[\ln \left(\frac{R}{r}\right)+L_{\mathrm{t}}\left(\frac{1}{R}+\frac{1}{r}\right)\right] \\
L_{\mathrm{t}}=\sqrt{\frac{\rho_{\mathrm{c}}}{R_{\mathrm{sh}}}}
\end{gathered}
$$

where $R_{\mathrm{sh}}$ represent the square resistance of $\mathrm{p}-\mathrm{GaN}, R$ and $r$ denote the radius of the outer and inner circular contact, $L_{\mathrm{t}}$ is the transfer distance. The total resistance is measured for various spacing contact and plotted as function of $\ln (R / r)$. The least squares linear curve fitting method is used to obtain line plot of $R_{\mathrm{t}}-\ln (R / r)$ data. The slope $K$ leads to $R_{\mathrm{sh}}=2 K \pi$, the $R_{\mathrm{t}}=R_{0}$ at $\ln (R / r)=0$. Thus, the specific resistance $\rho_{\mathrm{c}}$ can be obtained by Equation (3):

$$
\rho_{\mathrm{c}}=\frac{\pi r^{2} R_{0}^{2}}{2 K}
$$




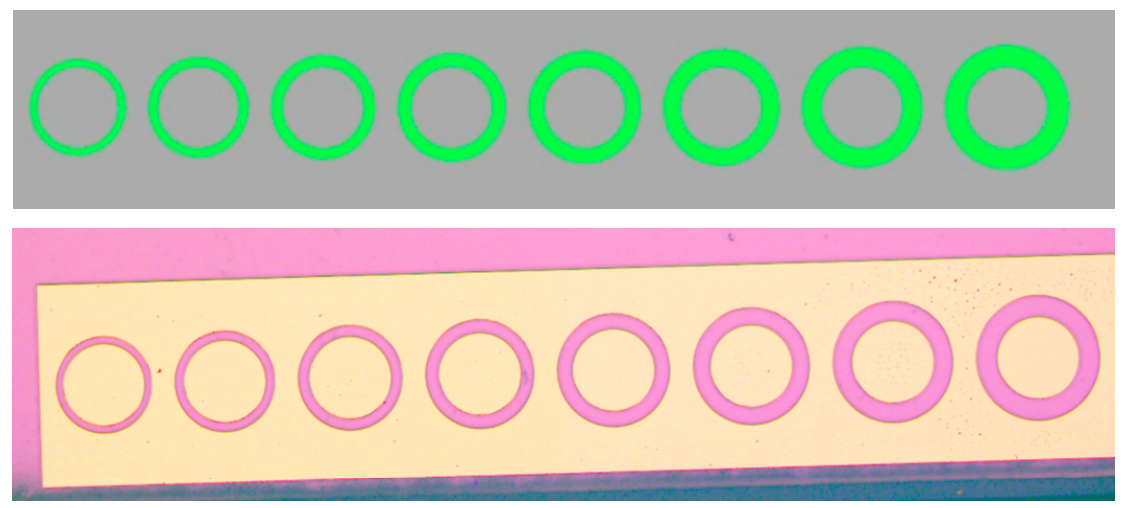

Figure 2. Schematic and optical image of the circular transmission line measurements (c-TLM) patterns used for the contact resistance measurements.

\section{Results and Discussion}

\subsection{Multi-Element Metal Alloy}

Figure 3 shows the $I-V$ characteristics of a wide variety of metal schemes heat-treated contacts, measured between the c-TLM ohmic pads with a gap spacing of $5 \mu \mathrm{m}$. The $I-V$ curves show non-ohmic features for $\mathrm{Pd} / \mathrm{Pt} / \mathrm{Au}$ sample, whereas the other linear $I-V$ curves indicate other samples are ohmic in nature. That indicates the multilayer metallization scheme based on all high work function metals $\mathrm{Pd} / \mathrm{Pt} / \mathrm{Au}$ does not have a good effect on all $\mathrm{p}-\mathrm{GaN}$ ohmic contacts, especially at this condition in our experiment. Figure 4 shows the c-TLM contact resistance measurements dependence on the $\ln (R / r)$ between $\mathrm{Pd} / \mathrm{Ni} / \mathrm{Au}$ metals pads. According to the c-TLM model, the specific contact resistance can be obtained from the intercept and slope of the curve shown in Figure 4. The specific contact resistance is calculated to be $7.3 \times 10^{-5} \Omega \cdot \mathrm{cm}^{2}$ for $\mathrm{Pd} / \mathrm{Ni} / \mathrm{Au}$ sample. Using the same method, the specific contact resistivity of other ohmic contact characteristic samples in Figure 4 are obtained: $3.6 \times 10^{-2}$, $2.8 \times 10^{-3}, 6.4 \times 10^{-4} \Omega \cdot \mathrm{cm}^{2}$ for $\mathrm{Ni} / \mathrm{Ag} / \mathrm{Zn}, \mathrm{Ni} / \mathrm{Ru} / \mathrm{Ag} / \mathrm{Au}$, and Ni/Au samples, respectively. The c-LTM measurements results are shown in Table 2. All contacts exhibited linear ohmic behaviors by p electrode metal films which contain $\mathrm{Ni}$ and $\mathrm{Au}$. These contacts achieve a low contact resistivity of less than $2.8 \times 10^{-3} \Omega \cdot \mathrm{cm}^{2}$, independent of the type of other contact metal variation. This suggests that the contact metal layer is not a key aspect of the ohmic contact formation in the Ni/Au-based contacts.

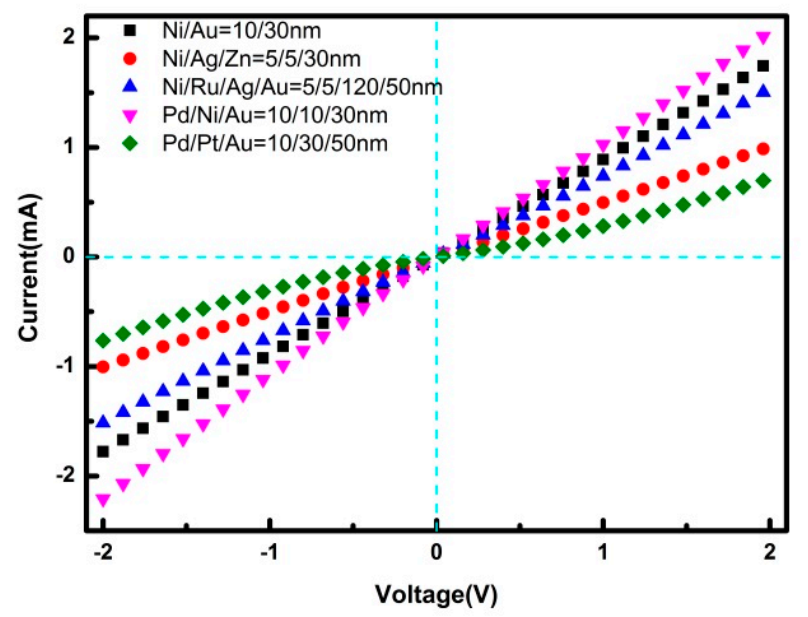

Figure 3. Measured $I-V$ curves for five different contact metallizations to $\mathrm{p}-\mathrm{GaN}$ on $\mathrm{GaN}$ laser diode, after annealing in a different atmosphere for $5 \mathrm{~min}$ at similar temperature. 


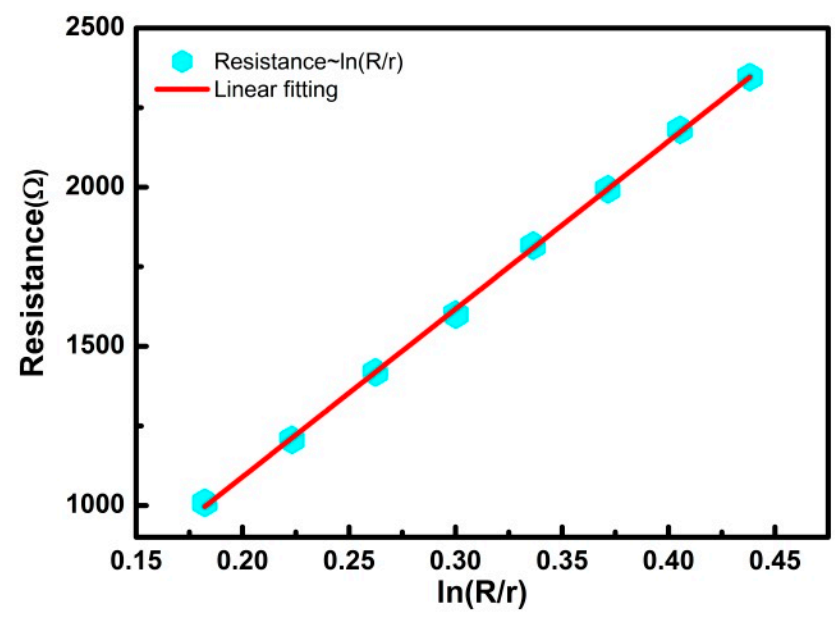

Figure 4. c-TLM data of $\mathrm{Pd}(10 \mathrm{~nm}) / \mathrm{Ni}(10 \mathrm{~nm}) / \mathrm{Au}(30 \mathrm{~nm})$ contacts on $\mathrm{GaN}$ laser diode sample in a mixture of nitrogen and oxygen ambient after annealing at $520{ }^{\circ} \mathrm{C}$ for $5 \mathrm{~min}$.

Table 2. The specific contact resistances detail of a variety of metal schemes.

\begin{tabular}{|c|c|c|c|c|}
\hline Film Structure & $\begin{array}{c}\text { Annealing } \\
\text { Temperature }\end{array}$ & $\begin{array}{l}\text { Annealing } \\
\text { Ambient }\end{array}$ & $\begin{array}{c}\text { Specific Contact } \\
\text { Resistances }\end{array}$ & Error \\
\hline $\begin{array}{l}\mathrm{Ni} / \mathrm{Au}=10 / 30 \mathrm{~nm} \\
\mathrm{Ni} / \mathrm{Au}=15 / 15 \mathrm{~nm} \\
\mathrm{Ni} / \mathrm{Au}=15 / 30 \mathrm{~nm} \\
\mathrm{Ni} / \mathrm{Au}=15 / 50 \mathrm{~nm}\end{array}$ & $520^{\circ} \mathrm{C}$ & $\mathrm{N}_{2}: \mathrm{O}_{2}=4: 1$ & $\begin{array}{l}7.5 \times 10^{-3} \Omega \cdot \mathrm{cm}^{2} \\
6.4 \times 10^{-4} \Omega \cdot \mathrm{cm}^{2} \\
4.3 \times 10^{-3} \Omega \cdot \mathrm{cm}^{2} \\
8.4 \times 10^{-3} \Omega \cdot \mathrm{cm}^{2}\end{array}$ & $\begin{array}{l}(-2.9,4.1) \times 10^{-3} \Omega \cdot \mathrm{cm}^{2} \\
(-3.1,4.2) \times 10^{-4} \Omega \cdot \mathrm{cm}^{2} \\
(-3.1,4.2) \times 10^{-3} \Omega \cdot \mathrm{cm}^{2} \\
(-3.3,4.1) \times 10^{-3} \Omega \cdot \mathrm{cm}^{2}\end{array}$ \\
\hline $\mathrm{Ni} / \mathrm{Ag} / \mathrm{Zn}=5 / 120 / 30 \mathrm{~nm}$ & $500^{\circ} \mathrm{C}$ & $\mathrm{N}_{2}: \mathrm{O}_{2}=4: 1$ & $3.6 \times 10^{-2} \Omega \cdot \mathrm{cm}^{2}$ & $(-0.3,0.5) \times 10^{-2} \Omega \cdot \mathrm{cm}^{2}$ \\
\hline $\mathrm{Ni} / \mathrm{Ru} / \mathrm{Ag} / \mathrm{Au}=5 / 5 / 120 / 50 \mathrm{~nm}$ & $520^{\circ} \mathrm{C}$ & $\mathrm{N}_{2}: \mathrm{O}_{2}=4: 1$ & $2.8 \times 10^{-3} \Omega \cdot \mathrm{cm}^{2}$ & $(-0.8,3.7) \times 10^{-3} \Omega \cdot \mathrm{cm}^{2}$ \\
\hline $\mathrm{Pd} / \mathrm{Ni} / \mathrm{Au}=10 / 10 / 30 \mathrm{~nm}$ & $520^{\circ} \mathrm{C}$ & $\mathrm{N}_{2}: \mathrm{O}_{2}=4: 1$ & $7.3 \times 10^{-5} \Omega \cdot \mathrm{cm}^{2}$ & $(-2.3,3.3) \times 10^{-5} \Omega \cdot \mathrm{cm}^{2}$ \\
\hline
\end{tabular}

For the Ni/Au two-element contact metal, the thickness of the Au layer has a weak influence on the contact performance, while the thickness of $\mathrm{Ni}$ has a great influence. The specific contact resistivity of $\mathrm{Ni} / \mathrm{Au}$ two-element ohmic contact characteristic samples in Table 1 are obtained: $6.4 \times 10^{-4}, 7.5 \times 10^{-3}$, $4.3 \times 10^{-3}, 8.4 \times 10^{-3} \Omega \cdot \mathrm{cm}^{2}$ for $\mathrm{Ni}(15 \mathrm{~nm}) / \mathrm{Au}(15 \mathrm{~nm}), \mathrm{Ni}(10 \mathrm{~nm}) / \mathrm{Au}(30 \mathrm{~nm}), \mathrm{Ni}(15 \mathrm{~nm}) / \mathrm{Au}(30 \mathrm{~nm})$, $\mathrm{Ni}(15 \mathrm{~nm}) / \mathrm{Au}(50 \mathrm{~nm})$ samples, respectively. The thickness of $\mathrm{Ni}$ is only changed by $5 \mathrm{~nm}$, and the contact resistivity is reduced by an order of magnitude, while the thickness of $\mathrm{Au}$ is changed, and the resistivity is maintained at the order of $10^{-3} \Omega \cdot \mathrm{cm}^{2}$. Otherwise, it is worth noting that contact resistivity decreases by one order of magnitude in a $\mathrm{Pd} / \mathrm{Ni} / \mathrm{Au}$ alloy system as the $\mathrm{p}$ electrode on $\mathrm{p}-\mathrm{GaN}$ using the Pd interlayer under Ni/Au metal layer. The improvement in ohmic characteristics can be attributed to the larger work function of metal $\mathrm{Pd}$ and the interfacial reactions occurring between the $\mathrm{Pd}, \mathrm{Ni}, \mathrm{Au}$, and $\mathrm{GaN}$, which extend into the GaN film with their alloy [41]. According to the previous literature [30], contact resistance to $\mathrm{p}-\mathrm{GaN}$ decreased exponentially as the work function increased. Pd and Ni reacted with $\mathrm{GaN}$, to form $\mathrm{Pd}$ - and $\mathrm{Ni}-\mathrm{Ga}$ related compound phases. The generation of $\mathrm{Ga}$ vacancies acting as acceptors in the near surface region of $\mathrm{p}-\mathrm{GaN}$ plays a role in reducing the contact resistivity. This is consistent with the results of previous studies [42-44]. However, the annealing temperature over than $350{ }^{\circ} \mathrm{C}$ had little effect on the transmission properties of these $\mathrm{Pd} / \mathrm{Ni} / \mathrm{Au}$ contacts. Meanwhile, when the alloy temperature is raised to $600{ }^{\circ} \mathrm{C}$, the $I-V$ curve becomes non-linear as well as the results in reference [41], and the resistivity and morphology of the contacts deteriorated, which are not shown in the figure.

Despite the significance of the surface morphology and the microstructure features to the physical properties, most of the published work $[20,24,41]$ on electrical properties of $p$ electrode metal alloy thin films lacks surface topography studies. To ensure good device performance of the laser diode, the surface morphology of the ohmic contact must be smooth to ensure good contact pattern clarity and adhesion to the metal overlay. Figure 5 shows the SEM micrographs of the Ni/Ag/Zn, Ni/Ru/Ag/Au, 
$\mathrm{Ni} / \mathrm{Au}, \mathrm{Pd} / \mathrm{Ni} / \mathrm{Au}$ samples annealed for $5 \mathrm{~min}$ in $\mathrm{O}_{2}$ and $\mathrm{N}_{2}$ or only $\mathrm{N}_{2}$ ambient. These SEM images in Figure 5, (a) Ni/Ag/Zn thin films and (b) Ni/Ru/Ag/Au thin films, show that these silver-containing ohmic electrodes have high surface roughness with irregular agglomerates. The formation of agglomeration by annealing is a typical phenomenon in Ag films, which involves the evolution of capillary instability, resulting in continuous exposure of the substrate. For the Ni/Ag/Zn thin films, the surface became rougher as compared with the $\mathrm{Ni} / \mathrm{Ru} / \mathrm{Ag} / \mathrm{Au}$ thin films sample, indicating that the non-uniform interdiffusion and intermixing of metals is more severe. The $\mathrm{Ru}$ interlayer between $\mathrm{Ni}$ and $\mathrm{Ag}$ can effectively block the interdiffusion between metals, which have been proven elsewhere [45]. Annealing reduces surface uniformity caused by metals between themselves or between metals and semiconductors due to differences in the thermodynamic properties of the materials. The surface of the (c) Ni/Au thin films and (d) $\mathrm{Pd} / \mathrm{Ni} / \mathrm{Au}$ thin films are much smoother than the Ag based metal systems. For Ni/Au thin films on GaN laser diode, the film morphology has significantly degraded, forming larger holes relative to the $\mathrm{Pd} / \mathrm{Ni} / \mathrm{Au}$ thin films. The $\mathrm{Pd} / \mathrm{Ni} / \mathrm{Au}$ thin films surface is very smooth and did not change, indicating that $\mathrm{Pd} / \mathrm{Ni} / \mathrm{Au}$ has excellent thermal stability and is suitable for a high power GaN laser diode.

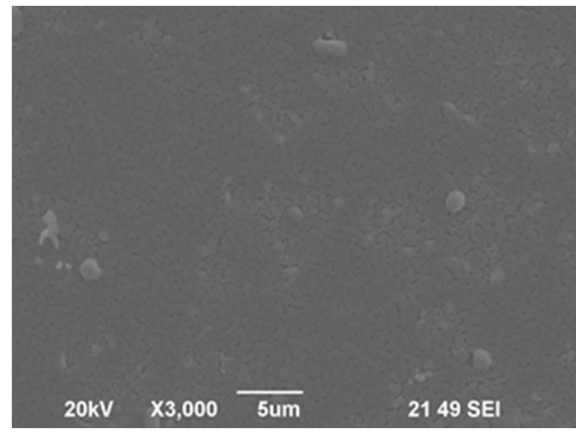

(a)

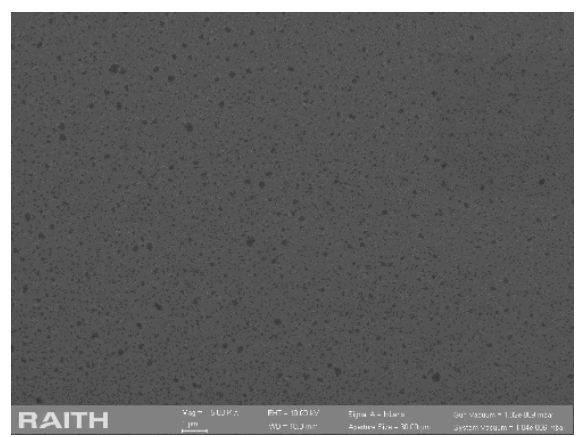

(c)

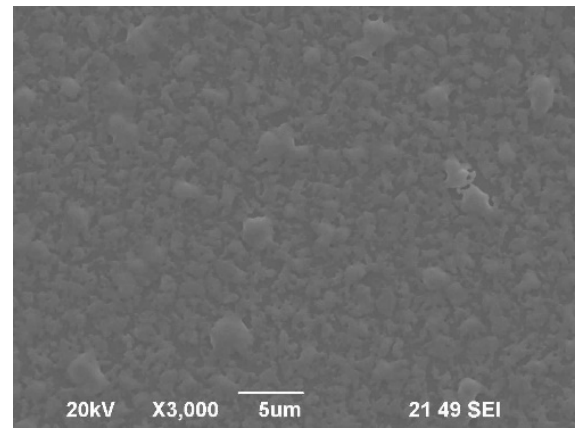

(b)

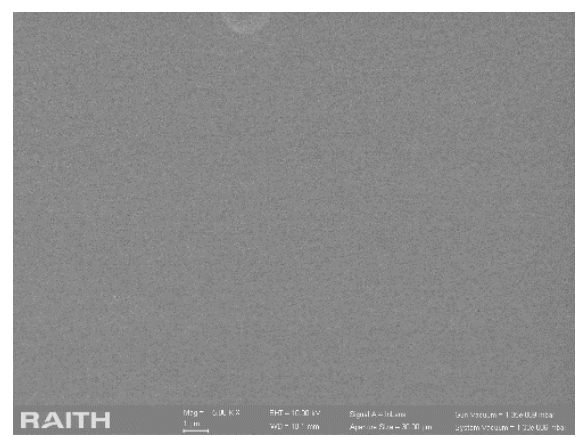

(d)

Figure 5. SEM image of $\mathrm{p}$ electrode metal thin films contacts on GaN laser diode, showing surface morphology after annealing for $5 \mathrm{~min}$. (a) Ni/Ag/Zn thin films; (b) Ni/Ru/Ag/Au thin films; (c) Ni/Au thin films; (d) Pd/Ni/Au thin films.

To further confirm the effect of surface morphology, we also used atomic force microscopy to measure root-mean-square (RMS) values of surface roughness to characterizing p electrode metal thin films surface topography as shown in Table 3. Figure 6 presents the $20 \times 20 \mu \mathrm{m}^{2}$ AFM images of the $\mathrm{Ni} / \mathrm{Au}$ and $\mathrm{Pd} / \mathrm{Ni} / \mathrm{Au}$ thin films annealed in $\mathrm{O}_{2}$ and $\mathrm{N}_{2}$ ambient at $520{ }^{\circ} \mathrm{C}$ for $5 \mathrm{~min}$. Before annealing, the thicknesses of the two thin films were measured by step profiler and found to be 39 and $48 \mathrm{~nm}$ for $\mathrm{Ni} / \mathrm{Au}$ and $\mathrm{Pd} / \mathrm{Ni} / \mathrm{Au}$ thin films, respectively. The surface roughness of the $\mathrm{Ni} / \mathrm{Au}$ and $\mathrm{Pd} / \mathrm{Ni} / \mathrm{Au}$ thin films is nearly the same as the GaN laser diode surface, which is lower than $1 \mathrm{~nm}$. This shows that our $\mathrm{GaN}$ laser diode surface is very flat and the vapor deposited metal film is very even and smooth. After annealing, the thin film roughness measured by AFM is found to be 13.64, $1.75 \mathrm{~nm}$; for the Ni/Au and $\mathrm{Pd} / \mathrm{Ni} / \mathrm{Au}$ thin films, after $\mathrm{O}_{2}$ and $\mathrm{N}_{2}$ ambient annealing, respectively, suggesting an effect induced by 
different microstructures. As shown in Figure 6, the surface topography profile is different for both $\mathrm{Ni} / \mathrm{Au}$ and $\mathrm{Pd} / \mathrm{Ni} / \mathrm{Au}$ thin films. The surface of the $\mathrm{Ni} / \mathrm{Au}$ sample has large pores and the surface undulation is large, while the surface of the $\mathrm{Pd} / \mathrm{Ni} / \mathrm{Au}$ sample has small pores and small undulations. The Pd insertion layer can further greatly reduce the roughness of the Ni/Au ohmic contact. The AFM test results were consistent with the SEM micrographs.

Table 3. The Atomic Force Microscope (AFM) results of Ni/Au and Pd/Ni/Au films.

\begin{tabular}{cccc}
\hline P Electrode & Annealing Temperature & Annealing Ambient & RMS \\
\hline $\begin{array}{c}\mathrm{Ni} / \mathrm{Au} \\
\mathrm{Pd} / \mathrm{Ni} / \mathrm{Au}\end{array}$ & non & non & $<1 \mathrm{~nm}$ \\
\hline $\mathrm{Ni} / \mathrm{Au}$ & $520{ }^{\circ} \mathrm{C}$ & $\mathrm{N}_{2}: \mathrm{O}_{2}=4: 1$ & $13.64 \mathrm{~nm}$ \\
\hline $\mathrm{Pd} / \mathrm{Ni} / \mathrm{Au}$ & $520{ }^{\circ} \mathrm{C}$ & $\mathrm{N}_{2}: \mathrm{O}_{2}=4: 1$ & $1.75 \mathrm{~nm}$ \\
\hline
\end{tabular}

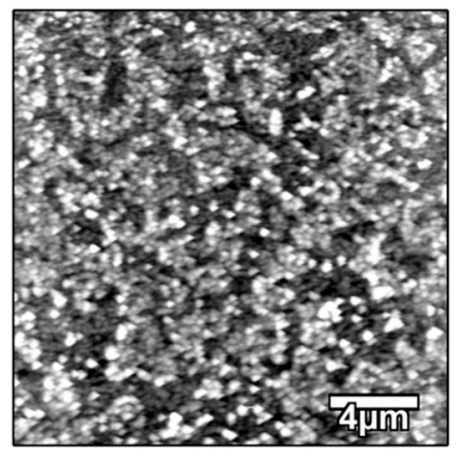

(a)

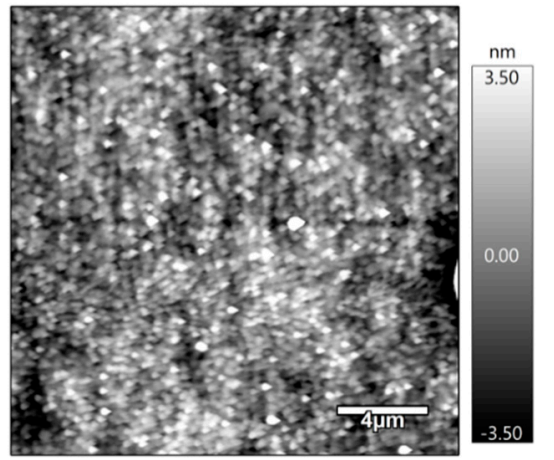

(b)

Figure 6. AFM image of (a) $\mathrm{Ni} / \mathrm{Au}$ and (b) $\mathrm{Pd} / \mathrm{Ni} / \mathrm{Au}$ thin films contacts on $\mathrm{GaN}$ laser diode, after annealing at $520^{\circ} \mathrm{C}$ for $5 \mathrm{~min}$ in $\mathrm{O}_{2}$ and $\mathrm{N}_{2}$ ambient.

\subsection{The Effect of Ni and Pd Thickness in Pd/Ni/Au}

Through the results of the above, we know that Ni/Au and $\mathrm{Pd} / \mathrm{Ni} / \mathrm{Au}$ metal systems have good intrinsic ohmic contact properties because of the smooth surface. Since the thickness of Au layer has little effect on the contact properties, the optimal contact performance can thus be obtained by properly adjusting the thickness of the Pd insertion layer and the thickness of the Ni layer. The electrical properties and morphological characterization of ohmic contact samples with different $\mathrm{Ni}$ thicknesses and different $\mathrm{Pd}$ thicknesses were systematically investigated, where the film parameters and annealing conditions of the various samples are shown in Table 4.

Table 4. The specific contact resistances of Pd/Ni/Au films with different thickness of Pd and Ni.

\begin{tabular}{ccccc}
\hline Film Structure & $\begin{array}{c}\text { Annealing } \\
\text { Temperature }\end{array}$ & $\begin{array}{c}\text { Annealing } \\
\text { Ambient }\end{array}$ & $\begin{array}{c}\text { Specific Contact } \\
\text { Resistances }\end{array}$ & Error \\
\hline $\mathrm{Pd} / \mathrm{Ni} / \mathrm{Au}=5 / 10 / 30 \mathrm{~nm}$ & & & $7.6 \times 10^{-4} \Omega \cdot \mathrm{cm}^{2}$ & $(-3.5,4.7) \times 10^{-4} \Omega \cdot \mathrm{cm}^{2}$ \\
$\mathrm{Pd} / \mathrm{Ni} / \mathrm{Au}=10 / 10 / 30 \mathrm{~nm}$ & & $7.3 \times 10^{-5} \Omega \cdot \mathrm{cm}^{2}$ & $(-2.3,3.3) \times 10^{-5} \Omega \cdot \mathrm{cm}^{2}$ \\
$\mathrm{Pd} / \mathrm{Ni} / \mathrm{Au}=15 / 10 / 30 \mathrm{~nm}$ & & $1.8 \times 10^{-4} \Omega \cdot \mathrm{cm}^{2}$ & $(-1.5,2.7) \times 10^{-4} \Omega \cdot \mathrm{cm}^{2}$ \\
$\mathrm{Pd} / \mathrm{Ni} / \mathrm{Au}=20 / 10 / 30 \mathrm{~nm}$ & $520^{\circ} \mathrm{C}$ & $\mathrm{N}_{2}: \mathrm{O}_{2}=4: 1$ & $2.1 \times 10^{-4} \Omega \cdot \mathrm{cm}^{2}$ & $(-1.6,2.7) \times 10^{-4} \Omega \cdot \mathrm{cm}^{2}$ \\
$\mathrm{Pd} / \mathrm{Ni} / \mathrm{Au}=10 / 5 / 30 \mathrm{~nm}$ & & & $4.1 \times 10^{-4} \Omega \cdot \mathrm{cm}^{2}$ & $(-1.7,3.0) \times 10^{-4} \Omega \cdot \mathrm{cm}^{2}$ \\
$\mathrm{Pd} / \mathrm{Ni} / \mathrm{Au}=10 / 15 / 30 \mathrm{~nm}$ & & & $1.3 \times 10^{-4} \Omega \cdot \mathrm{cm}^{2}$ & $(-1.5,2.7) \times 10^{-4} \Omega \cdot \mathrm{cm}^{2}$ \\
$\mathrm{Pd} / \mathrm{Ni} / \mathrm{Au}=10 / 20 / 30 \mathrm{~nm}$ & & & $2.5 \times 10^{-4} \Omega \cdot \mathrm{cm}^{2}$ & $(-1.6,2.7) \times 10^{-4} \Omega \cdot \mathrm{cm}^{2}$ \\
\hline
\end{tabular}

In order to exclude the effects of annealing conditions, the samples were subjected to the same annealing environment. Similarly, surface topography and roughness were tested by SEM and AFM. There is almost no difference in the surface topography of all samples and the roughness of the samples. There are small holes on the surface of all samples, and the roughness is about $2 \mathrm{~nm}$. 
Figure 7 presents the current-voltage $(I-V)$ characteristics for $\mathrm{Pd} / \mathrm{Ni} / \mathrm{Au}$ samples with different $\mathrm{Ni}$ thicknesses or different Pd thicknesses. The specific contact resistances of the samples in Figure $7 \mathrm{a}$ were calculated by the c-TLM model: $4.1 \times 10^{-4}, 7.3 \times 10^{-5}, 1.3 \times 10^{-4}, 2.5 \times 10^{-4} \Omega \cdot \mathrm{cm}^{2}$, for Pd/Ni/Au samples with $\mathrm{Ni}$ metal thickness gradually increasing from 5 to $2 \mathrm{~nm}$. The same way, the specific contact resistivity of other ohmic contact characteristic samples in Figure $7 \mathrm{~b}$ were obtained to be $7.6 \times 10^{-4}, 7.3 \times 10^{-5}, 1.8 \times 10^{-4}, 2.1 \times 10^{-4} \Omega \cdot \mathrm{cm}^{2}$, for Pd/Ni/Au samples with Pd metal thickness gradually increasing from 5 to $20 \mathrm{~nm}$, respectively. The specific contact resistivity of $\mathrm{Pd} / \mathrm{Ni} / \mathrm{Au}$ sample starts to increase when the thickness of $\mathrm{Ni}$ is gradually increased by $10 \mathrm{~nm}$. A similar trend is also observed when the thickness of the Pd changes. The lowest specific contact resistivity of $\mathrm{Pd} / \mathrm{Ni} / \mathrm{Au}$ sample is obtained when the thickness of both $\mathrm{Ni}$ and $\mathrm{Pd}$ is $10 \mathrm{~nm}$. The other samples are several times larger or an order of magnitude larger than that of $\operatorname{Pd}(10 \mathrm{~nm}) / \mathrm{Ni}(10 \mathrm{~nm}) / \mathrm{Au}(30 \mathrm{~nm})$ sample. In other words, the thickness of Au remains constant. Appropriately increasing the thickness of $\mathrm{Pd}$ and $\mathrm{Ni}$, the contact resistivity is improved. As mentioned in reference [46], the Au layer plays a role in spreading the injection current while the Ni layer plays a role in reducing the Schottky barrier height (SBH) in $\mathrm{Ni} / \mathrm{Au}$ ohmic contacts. The high contact resistance in our work can be attributed to Pd or Ni not being thick enough to reduce the SBH efficiently. When the thickness of Pd and Ni layer is changed from 5 to $10 \mathrm{~nm}$, the contact resistance increases with the thickness of the $\mathrm{Pd}$ and Ni layer in the $\mathrm{Pd} / \mathrm{Ni} / \mathrm{Au}$ trilayer. When the thickness of the Pd or Ni layer in the $\mathrm{Pd} / \mathrm{Ni} / \mathrm{Au}$ trilayer is $10 \mathrm{~nm}$, the diffusion of $\mathrm{Au}$ atoms to the metal/semiconductor interface is easy, so that relative low contact resistance can be obtained. Further increasing the thickness of Pd or Ni will impede the diffusion of Au toward to the metal/semiconductor interface, which is also disadvantageous for forming $\mathrm{NiO}$ and $\mathrm{Pd}-\mathrm{Ni}-\mathrm{Ga}$ related compounds, and leads to an increase in contact resistance. A similar phenomenon also occurs on blue LEDs [46]. Therefore, only a suitable electrode thickness is advantageous for forming a good ohmic contact and reducing the specific contact resistivity.

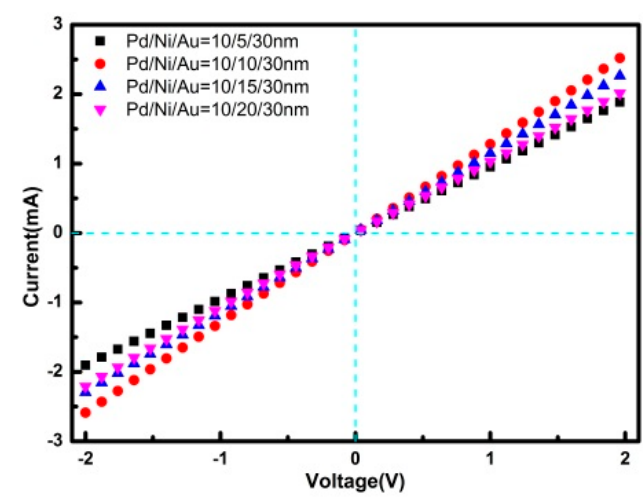

(a)

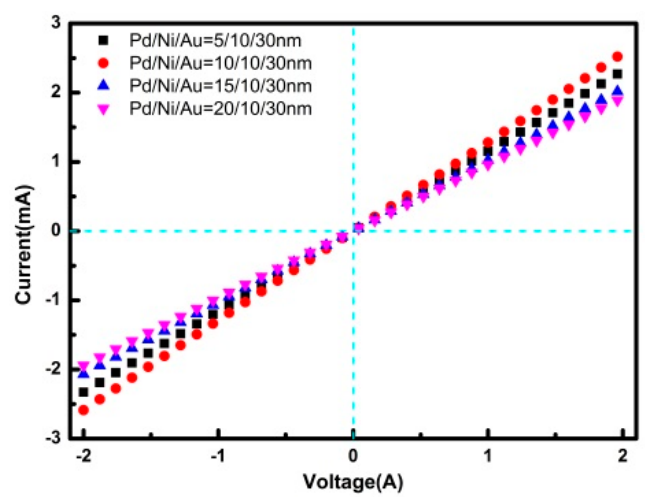

(b)

Figure 7. $I-V$ characteristics of $\mathrm{Pd} / \mathrm{Ni} / \mathrm{Au}$ contacts on $\mathrm{GaN}$ laser diodes alloyed at different $\mathrm{Ni}$ or Pd thicknesses: (a) Different Ni thicknesses in Pd/Ni/Au contacts; (b) different Pd thicknesses in $\mathrm{Pd} / \mathrm{Ni} / \mathrm{Au}$ contacts.

It is worth noting that all the annealed $\mathrm{Pd} / \mathrm{Ni} / \mathrm{Au}$ contacts produce somewhat similar low resistances on GaN based laser diode, all the specific contact resistances are stable at the order of $\sim 10^{-4} \Omega \cdot \mathrm{cm}^{2}$. By optimizing the thickness of the metal layer, the contact resistivity achieved could be $\sim 10^{-5} \Omega \cdot \mathrm{cm}^{2}$, which is lower by one order of magnitude compared to UCSB GaN lasers [47,48]. The results show that the use of the Pd interlayer plays a crucial role in improving ohmic contact characteristics. From the viewpoint of device processing, it is very important to have a stable and wider window for good ohmic formation on $\mathrm{GaN}$ laser diode. 


\subsection{The Effect of $\mathrm{KOH}$ Pretreatment}

The chemical adsorption of oxygen atoms on the surface of compound semiconductors is very active, resulting in the production of natural oxides on the surface [49]. Surface oxides can serve as a barrier to carrier transport from metal to semiconductor, resulting in an increase in ohmic contact resistivity. Therefore, the contact resistivity on the p-type GaN can be lowered by the surface treatment of removing the oxide before the metal deposition. The chemical composition of the GaN laser diode surface is characterized by EDX before the surface treatment. Figure 8 displays the EDX of GaN laser diode surface. The EDX analysis proves that there exists a small amount of oxygen on the surface of the GaN sample. Note that in the absence of TEM and XPS, the precise characteristic of the oxide layer on the GaN surface is difficult to determine since it is only $2 \mathrm{~nm}$ thin during the growth process.

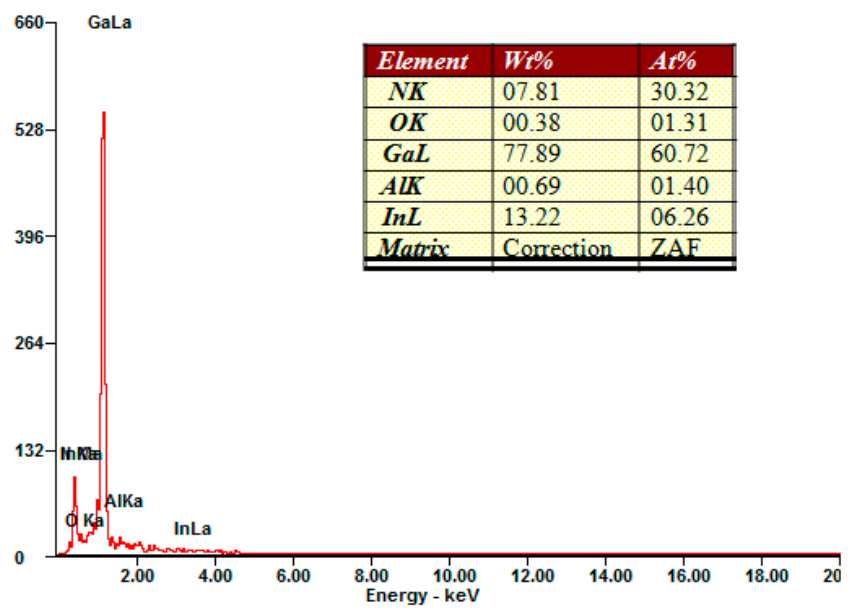

Figure 8. Energy Dispersive X-ray (EDX) of GaN based laser diode surface.

In this work, two types of sample were prepared. One set is prepared by dipping the p-type GaN in $\mathrm{KOH}$ solution at $80^{\circ} \mathrm{C}$ for $5 \mathrm{~min}$, which is conventionally used for surface treatment prior to the deposition of ohmic metals (KOH-treated sample). The other set is the $\mathrm{Pd}(10 \mathrm{~nm}) / \mathrm{Ni}(10 \mathrm{~nm}) / \mathrm{Au}(30 \mathrm{~nm})$ contact without the chemical treatment sample. Figure 9 shows current-voltage characteristics measured between the $\mathrm{Pd}(10 \mathrm{~nm}) / \mathrm{Ni}(10 \mathrm{~nm}) / \mathrm{Au}(30 \mathrm{~nm})$ contact pads for both untreated and the $\mathrm{KOH}$-treated $\mathrm{GaN}$ laser diode samples. The specific contact resistivity taken from the gradients and intercepts in the plots are determined to be $1.66 \times 10^{-5} \Omega \cdot \mathrm{cm}^{2}$ for the $\mathrm{KOH}$-treated sample and $7.3 \times 10^{-5} \Omega \cdot \mathrm{cm}^{2}$ for the untreated sample. Note that contact resistivity decreases by 4.5 times by the surface treatment using $\mathrm{KOH}$ solution. The contact resistivity obtained is the lowest value of the result of the previous $\mathrm{Pd} / \mathrm{Ni} / \mathrm{Au}$ ohmic contact on p-type $\mathrm{GaN}$ compared with previous report $[41,50]$. $\mathrm{KOH}$-based chemical treatment has proven to be effective in removing surface oxides and other carbonaceous contaminants $[31,34,51]$. It has been reported that $\mathrm{N}$ vacancies can act as donors in the $\mathrm{GaN}$ [52] with Ga vacancies acting as acceptors. Gallium hydroxide is formed by reacting GaN with $\mathrm{OH}$ in a $\mathrm{KOH}$ solution to preferentially remove gallium oxide. Selective removal of gallium oxide by $\mathrm{KOH}$ treatment results in the formation of acceptor-like Ga vacancies, causing the surface Fermi level to move toward the valence band edge and resulting in a much smaller surface barrier height to $\mathrm{p}-\mathrm{GaN}$ [34]. Since the metal contact resistance decreases as the surface barrier height decreases, the smaller surface barrier height on the $\mathrm{p}-\mathrm{GaN}$ produced by the $\mathrm{KOH}$ treatment can play an important role in reducing the subsequent metal contact resistivity. The tunneling barrier for carrier injection from metal to p-type $\mathrm{GaN}$ is decreased and the hole tunneling probability at the $\mathrm{Pd} / \mathrm{p}-\mathrm{GaN}$ interface is increased, resulting in a decrease in contact resistivity. Thus, it is suggested that the decrease in contact resistivity in Figure 8 is related to the removal of surface oxides formed on the surface of GaN laser diode during epitaxial growth. 


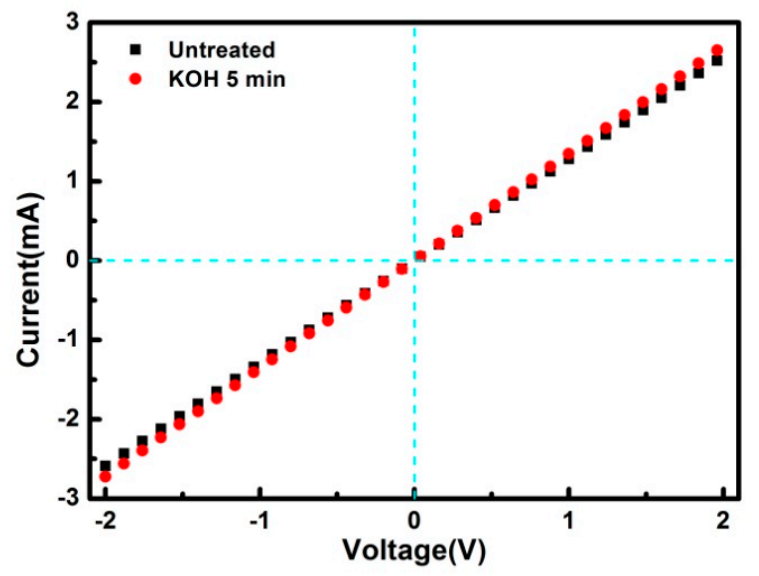

Figure 9. Measured $I-V$ curves for untreated and the $\mathrm{KOH}$-treated before $\mathrm{Pd}(10 \mathrm{~nm}) / \mathrm{Ni}(10 \mathrm{~nm}) / \mathrm{Au}(30 \mathrm{~nm})$ contact evaporation on $\mathrm{GaN}$ laser diode.

\subsection{Performance Improvement of GaN Laser Power by Pd/Ni/Au Metallization}

Figure 10 shows the output light peak power as a function of the pulsed injection current of the two GaN-based violet LDs: original and optimized samples. The structure parameters and growth conditions for original and optimized samples are the same, while original and optimized samples have a difference in ohmic contact process. The original sample has a conventional Ni/Au contact as the $\mathrm{p}$ electrode, and the optimized sample pretreated by $\mathrm{KOH}$ solution has the lower resistivity $\mathrm{Pd} / \mathrm{Ni} / \mathrm{Au}$ metal electrode. As shown in Figure 10, the two output power curves were very different. It is found that light power increases sharply and lasing starts when the injection current is higher than $500 \mathrm{~mA}$ for the optimized sample, and higher than $800 \mathrm{~mA}$ for the original sample. So, the threshold currents of original and optimized samples are 800 and $500 \mathrm{~mA}$, and the corresponding threshold current density is 6.67 and $4.17 \mathrm{kA} / \mathrm{cm}^{2}$, respectively. The slope efficiencies of original and optimized samples are 0.402 and $0.486 \mathrm{~A} / \mathrm{W}$, respectively. The huge reduction in threshold current and the increase in slope efficiency are clearly caused by a large improvement in contact performance. Obviously, the performance of the optimized sample is much better than the original sample. The output power of optimized sample is improved by 1.95 times that of the original sample at $1.2 \mathrm{~A}$.

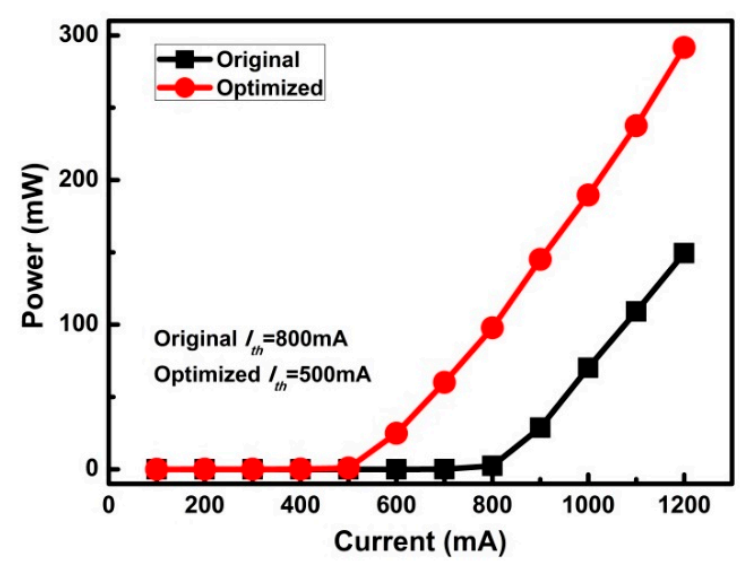

Figure 10. The output light peak power as a function of the pulsed injection current of the original and optimized GaN-based laser diodes.

Subsequently, we carried out the same experiment on the subsequent batches of GaN laser samples, and obtained similar trends and results, indicating that the $\mathrm{Pd} / \mathrm{Ni} / \mathrm{Au}$ ohmic contact metal system has good repeatability and stability, and can be applied to large-scale preparation of GaN laser diodes. Thus, by controlling the thickness of Pd and Ni metal layer and the surface treatment using 
$\mathrm{KOH}$ solution, and optimizing the annealing conditions, it is possible to form a low resistance stable ohmic contact to $\mathrm{GaN}$ laser diode with the $\mathrm{Pd} / \mathrm{Ni} / \mathrm{Au}$ contact layer and reliable device performance can be achieved.

\section{Conclusions}

We have systematically investigated the influence of different metal systems on the ohmic contact of the $\mathrm{GaN}$ laser by a series of four ohmic contact metal experiments. $\mathrm{Pd} / \mathrm{Ni} / \mathrm{Au}$ metallization ohmic contact with a suitable electrode thickness has the lowest specific contact resistance of $7.5 \times 10^{-5} \Omega \cdot \mathrm{cm}^{2}$, which is due to the reduction of schottky barrier heights by larger work function of metal Pd, and the $\mathrm{Pd}-$ and Ni-Ga related compound phases plays a role in reducing the contact resistivity. Meanwhile, increasing the $\mathrm{KOH}$ solution pretreatment process can further reduce the specific contact resistivity to $1.66 \times 10^{-5} \Omega \cdot \mathrm{cm}^{2}$, which is lower by one order of magnitude compared to UCSB GaN lasers, indicating that the surface treatment using $\mathrm{KOH}$ solution is very effective to remove surface oxide and increase the hole tunneling probability. SEM and AFM data of $\mathrm{Pd} / \mathrm{Ni} / \mathrm{Au}$ ohmic contacts are presented, showing that the Pd layer dramatically improved the morphological stability of the metallization stack by preventing the nickel and gold interchange. Combining the above factors, using $\mathrm{KOH}$ solution-pretreated $\mathrm{Pd}(10 \mathrm{~nm}) / \mathrm{Ni}(10 \mathrm{~nm}) / \mathrm{Au}(30 \mathrm{~nm})$ as the ohmic contact on $\mathrm{GaN}$ laser diode, the power of the GaN laser diode is increased by 1.95 times compared to the conventional ohmic contact $\mathrm{Ni}(10 \mathrm{~nm}) / \mathrm{Au}(30 \mathrm{~nm})$. The low resistance and stable $\mathrm{Pd} / \mathrm{Ni} / \mathrm{Au}$ contacts are versatile and can extend to other structures of GaN-based lasers, and can represent a promising solution for fabricating high performance laser diodes.

Author Contributions: Conceptualization, W.W. and S.S.; Methodology, W.X.; Validation, W.W. and S.S.; Formal Analysis, W.X.; Investigation, W.W., W.X., H.Y., M.L., X.L. and Z.D.; Resources, W.W. and D.Z.; Data Curation, W.W. and W.X.; Writing-Original Draft Preparation, W.W.; Writing-Review and Editing, W.W. and S.S.; Supervision, J.L.

Funding: This research was funded by the Science Challenge Project (No. TZ2016003-2), the National Natural Science Foundation of China (No. 61504126), and the National Key R\&D Program of China (No. 2017YFB0403103).

Acknowledgments: The authors would like to thank Nanofabrication facility in Suzhou Institute of Nano-tech and Nano-bionics (CAS) for equipment access.

Conflicts of Interest: The authors declare no conflict of interest.

\section{References}

1. Nakamura, S.; Senoh, M.; Nagahama, S.I.; Iwasa, N.; Yamada, T.; Matsushita, T.; Kiyoku, H.; Sugimoto, Y.; Kozaki, T.; Umemoto, H.; et al. InGaN/GaN/AlGaN-based laser diodes with modulation-doped strained-layer superlattices grown on an epitaxially laterally overgrown GaN substrate. Appl. Phys. Lett. 1998, 72, $211-213$. [CrossRef]

2. Schmidt, M.C.; Kim, K.C.; Farrell, R.M.; Feezell, D.F.; Cohen, D.A.; Saito, M.; Fujito, K.; Speck, J.S.; DenBaars, S.P.; Nakamura, S. Demonstration of nonpolar m-plane InGaN/GaN laser diodes. Jpn. J. Appl. Phys. 2007, 46, L190-L191. [CrossRef]

3. Chi, Y.C.; Hsieh, D.H.; Tsai, C.T.; Chen, H.Y.; Kuo, H.C.; Lin, G.R. 450-nm GaN laser diode enables high-speed visible light communication with 9-Gbps QAM-OFDM. Opt. Express 2015, 23, 13051-13059. [CrossRef]

4. Nakamura, S.; Mukai, T.; Senoh, M. High-power GaN pn junction blue-light-emitting diodes. Jpn. J. Appl. Phys. 1991, 30, L1998-L2001. [CrossRef]

5. Guha, S.; Bojarczuk, N.A. Ultraviolet and violet GaN light emitting diodes on silicon. Appl. Phys. Lett. 1998, 72, 415-417. [CrossRef]

6. Nakamura, S.; Mukai, T.; Senoh, M. Candela class high brightness InGaN/AlGaN double heterostructure blue light emitting diodes. Appl. Phys. Lett. 1994, 64, 1687-1689. [CrossRef]

7. Yonkee, B.P.; Young, E.C.; DenBaars, S.P.; Nakamura, S.; Speck, J.S. Silver free III-nitride flip chip light-emitting-diode with wall plug efficiency over 70\% utilizing a GaN tunnel junction. Appl. Phys. Lett. 2016, 109, 191104. [CrossRef]

8. Wu, Y.F.; Kapolnek, D.; Ibbetson, J.P.; Parikh, P.; Keller, B.P.; Mishra, U.K. Very-high power density AlGaN/GaN HEMTs. IEEE Trans. Electron Devices 2001, 48, 586-590. [CrossRef] 
9. Kizilyalli, I.C.; Edwards, A.P.; Aktas, O.; Prunty, T.; Bour, D. Vertical power pn diodes based on bulk GaN. IEEE Trans. Electron Devices 2015, 62, 414-422. [CrossRef]

10. Su, Y.K.; Chiou, Y.Z.; Juang, F.S.; Chang, S.J.; Sheu, J.K. GaN and InGaN metal-semiconductor-metal photodetectors with different Schottky contact metals. Jpn. J. Appl. Phys. 2001, 40, 2996-2999. [CrossRef]

11. Chen, Q.; Khan, M.A.; Sun, C.J.; Yang, J.W. Visible-blind ultraviolet photodetectors based on GaN pn junctions. Electron. Lett. 1995, 31, 1781-1782. [CrossRef]

12. Li, K.H.; Fu, W.Y.; Cheung, Y.F.; Wong, K.K.Y.; Wang, Y.; Lau, K.M.; Choi, H.W. Monolithically integrated InGaN/GaN light-emitting diodes, photodetectors, and waveguides on Si substrate. Optica 2018, 5, 564-569. [CrossRef]

13. Ng, H.M.; Doppalapudi, D.; Korakakis, D.; Singh, R.; Moustakas, T.D. MBE growth and doping of III-V nitrides. J. Cryst. Growth 1998, 189, 349-353. [CrossRef]

14. Trexler, J.T.; Pearton, S.J.; Holloway, P.H.; Mier, M.; Evans, K.; Karlicek, R. Comparison of Ni/Au, Pd/Au, Cr/Au metallizations for ohmic contacts to p-GaN. MRS Online Proc. Libr. Arch. 1996, 449, 1091-1096. [CrossRef]

15. Voss, L.; Khanna, R.; Pearton, S.J.; Ren, F.; Kravchenko, I. Improved thermally stable ohmic contacts on p-GaN based on $\mathrm{W}_{2}$ B. Appl. Phys. Lett. 2006, 88, 012104. [CrossRef]

16. Chang, K.M.; Chu, J.Y.; Cheng, C.C. Investigation of indium-tin-oxide ohmic contact to p-GaN and its application to high-brightness GaN-based light-emitting diodes. Solid-State Electron. 2005, 49, 1381-1386. [CrossRef]

17. Chen, L.C.; Chen, F.R.; Kai, J.J.; Chang, L.; Ho, J.K.; Jong, C.S.; Chiu, C.C.; Huang, C.N.; Chen, C.Y.; Shih, K.K. Microstructural investigation of oxidized Ni/Au ohmic contact to p-type GaN. J. Appl. Phys. 1996, 86, 3826-3832. [CrossRef]

18. Chen, L.C.; Ho, J.K.; Jong, C.S.; Chiu, C.C.; Shih, K.K.; Chen, F.R.; Kai, J.J.; Chang, L. Oxidized Ni/Pt and Ni/Au ohmic contacts to p-type GaN. Appl. Phys. Lett. 2000, 76, 3703-3705. [CrossRef]

19. Oh, M.S.; Hwang, D.K.; Lim, J.H.; Kang, C.G.; Park, S.J. Low resistance nonalloyed Ni/Au Ohmic contacts to p-GaN irradiated by KrF excimer laser. Appl. Phys. Lett. 2006, 89, 042107. [CrossRef]

20. Zhou, L.; Lanford, W.; Ping, A.T.; Adesida, I.; Yang, J.W.; Khan, A. Low resistance Ti/Pt/Au ohmic contacts to p-type GaN. Appl. Phys. Lett. 2000, 76, 3451-3453. [CrossRef]

21. Kim, J.K.; Lee, J.L.; Lee, J.W.; Eoi Shin, H.; Jo Park, Y.; Kim, T. Low resistance Pd/Au ohmic contacts to p-type GaN using surface treatment. Appl. Phys. Lett. 1998, 73, 2953-2955. [CrossRef]

22. Kumakura, K.; Toshiki, M.; Naoki, K. Low-resistance nonalloyed ohmic contact to p-type GaN using strained InGaN contact layer. Appl. Phys. Lett. 2001, 79, 2588-2590. [CrossRef]

23. Jang, J.S.; Park, S.J.; Seong, T.Y. Metallization scheme for highly low-resistance, transparent, and thermally stable ohmic contacts to p-GaN. Appl. Phys. Lett. 2000, 76, 2898-2900. [CrossRef]

24. Kwak, J.S.; Nam, O.H.; Park, Y. Temperature-dependent contact resistivity of the nonalloyed ohmic contacts to p-GaN. J. Appl. Phys. 2004, 95, 5917-5919. [CrossRef]

25. Kwak, J.S.; Cho, J.; Chae, S.; Choi, K.; Sung, Y.; Lee, S.; Nam, O.H.; Park, Y. Carrier transport mechanism of $\mathrm{Pd} / \mathrm{Pt} / \mathrm{Au}$ ohmic contacts to $\mathrm{p}-\mathrm{GaN}$ in InGaN laser diode. Phys. Status Solidi A 2002, 194, 587-590. [CrossRef]

26. Chu, C.F.; Yu, C.C.; Wang, Y.K.; Tsai, J.Y.; Lai, F.I.; Wang, S.C. Low-resistance ohmic contacts on p-type GaN using Ni/Pd/Au metallization. Appl. Phys. Lett. 2000, 77, 3423-3425. [CrossRef]

27. Feng, M.; Sun, Q.; Liu, J.; Li, Z.; Zhou, Y.; Gao, H.; Zhang, S.; Yang, H. Al-free cladding-layer blue laser diodes with a low aspect ratio in far-field beam pattern. J. Semicond. 2018, 39, 084004. [CrossRef]

28. Shan Hsu, P.; Hardy, M.T.; Wu, F.; Koslow, I.; Young, E.C.; Romanov, A.E.; Fujito, K.; Feezell, D.F.; DenBaars, S.P.; Speck, J.S.; et al. $444.9 \mathrm{~nm}$ semipolar (1122) laser diode grown on an intentionally stress relaxed InGaN waveguiding layer. Appl. Phys. Lett. 2012, 100, 021104. [CrossRef]

29. Feng, M.; Wang, J.; Zhou, R.; Sun, Q.; Gao, H.; Zhou, Y.; Liu, J.; Huang, Y.; Zhang, H.; Ikeda, M.; et al. On-chip integration of gan-based laser, modulator, and photodetector grown on Si. IEEE J. Sel. Top. Quantum Electron. 2018, 24, 1-5. [CrossRef]

30. Ishikawa, H.; Kobayashi, S.; Koide, Y.; Yamasaki, S.; Nagai, S.; Umezaki, J.; Koike, M.; Murakami, M. Effects of surface treatments and metal work functions on electrical properties at $p-\mathrm{GaN} / \mathrm{metal}$ interfaces. J. Appl. Phys. 1997, 81, 1315-1322. [CrossRef]

31. Lee, J.L.; Kim, J.K.; Lee, J.W.; Park, Y.J.; Kim, T. Effect of surface treatment by KOH solution on ohmic contact formation of p-type GaN. Solid-State Electron. 1999, 43, 435-438. [CrossRef] 
32. Lee, J.L.; Weber, M.; Kim, J.K.; Lee, J.W.; Park, Y.J.; Kim, T.; Lynn, K. Ohmic contact formation mechanism of nonalloyed Pd contacts to p-type GaN observed by positron annihilation spectroscopy. Appl. Phys. Lett. 1999, 74, 2289-2291. [CrossRef]

33. Song, J.O.; Leem, D.S.; Kwak, J.S.; Nam, O.H.; Park, Y.; Seong, T.Y. High-quality nonalloyed rhodium-based ohmic contacts to p-type GaN. Appl. Phys. Lett. 2003, 83, 2372-2374. [CrossRef]

34. Sun, J.; Rickert, K.A.; Redwing, J.M.; Ellis, A.B.; Himpsel, F.J.; Kuech, T.F. p-GaN surface treatments for metal contacts. Appl. Phys. Lett. 2000, 76, 415-417. [CrossRef]

35. Pearton, S.J.; Zolper, J.C.; Shul, R.J.; Ren, F. GaN: Processing, defects, and devices. J. Appl. Phys. 1999, 86, 1-78. [CrossRef]

36. Lee, J.L.; Kim, J.K. Ohmic contact formation mechanism of Pd nonalloyed contacts on p-type GaN. J. Vac. Sci. Technol. B 2000, 147, 2667-2670. [CrossRef]

37. Lee, C.S.; Lin, Y.J.; Lee, C.T. Investigation of oxidation mechanism for ohmic formation in Ni/Au contacts to p-type GaN layers. Appl. Phys. Lett. 2001, 79, 3815-3817. [CrossRef]

38. Li, X.; Zhao, D.G.; Jiang, D.S.; Yang, J.; Chen, P.; Liu, Z.S.; Zhu, J.J.; Liu, W.; He, X.G.; Li, X.J.; et al. Analysis of localization effect in blue-violet light emitting InGaN/GaN multiple quantum wells with different well widths. Chin. Phys. B 2017, 26, 017805. [CrossRef]

39. Weimar, A.; Lell, A.; Brüderl, G.; Bader, S.; Harle, V. Investigation of low-resistance metal contacts on p-type GaN using the linear and circular transmission line method. Phys. Status Solidi A 2001, 183, 169-175. [CrossRef]

40. Marlow, G.S.; Das, M.B. The effects of contact size and non-zero metal resistance on the determination of specific contact resistance. Solid-State Electron. 1982, 25, 91-94. [CrossRef]

41. Cho, H.K.; Hossain, T.; Bae, J.W.; Adesida, I. Characterization of Pd/Ni/Au ohmic contacts on p-GaN. Solid-State Electron. 2005, 49, 774-778. [CrossRef]

42. Jang, J.S.; Chang, I.S.; Kim, H.K.; Seong, T.Y.; Lee, S.; Park, S.J. Low-resistance Pt/Ni/Au ohmic contacts to p-type GaN. Appl. Phys. Lett. 1999, 74, 70-72. [CrossRef]

43. Jang, H.W.; Kim, K.H.; Kim, J.K.; Hwang, S.; Yang, J.J.; Lee, K.J. Low-resistance and thermally stable ohmic contact on p-type GaN using Pd/Ni metallization. Appl. Phys. Lett. 2001, 79, 1822-1824. [CrossRef]

44. Jang, J.S.; Park, S.J.; Seong, T.Y. Interfacial reaction of Ni/Pt/Au contact schemes to p-type GaN. J. Electrochem. Soc. 1999, 146, 3425-3428. [CrossRef]

45. Jang, H.W.; Son, J.H.; Lee, J.L. Formation of high-quality Ag-based ohmic contacts to p-type GaN. J. Electrochem. Soc. 2008, 155, H563-H568. [CrossRef]

46. Qin, Z.X.; Chen, Z.Z.; Zhang, H.X.; Ding, X.M.; Hu, X.D.; Yu, T.J.; Zhang, G.Y. The role of Ni and Au on transparent film of blue LEDs. Solid-State Electron. 2005, 47, 1741-1743. [CrossRef]

47. Yonkee, B.P.; Young, E.C.; Lee, C.; Leonard, J.T.; Denbaars, S.P.; Speck, J.S.; Nakamura, S. Demonstration of a III-nitride edge-emitting laser diode utilizing a GaN tunnel junction contact. Opt. Express 2016, 24, 7816-7822. [CrossRef]

48. Myzaferi, A.; Reading, A.H.; Farrell, R.M.; Cohen, D.A.; Nakamura, S.; Denbaars, S.P. Semipolar III-nitride laser diodes with zinc oxide cladding. Opt. Express 2017, 25, 16922-16930. [CrossRef]

49. Lee, J.L.; Wei, L.; Tanigawa, S.; Oigawa, H.; Nannichi, Y. Evidence for the passivation effect in (NH4) ${ }_{2} \mathrm{~S}_{x}$-treated GaAs observed by slow positrons. Appl. Phys. Lett. 1991, 58, 1167-1169. [CrossRef]

50. Chor, E.F.; Zhang, D.; Gong, H.; Chen, G.L.; Liew, T.Y.F. Electrical characterization and metallurgical analysis of Pd-containing multilayer contacts on GaN. J. Appl. Phys. 2001, 90, 1242-1249. [CrossRef]

51. Zhang, A.P.; Luo, B.; Johnson, J.W.; Ren, F.; Han, J.; Pearton, S.J. Role of annealing conditions and surface treatment on ohmic contacts to $\mathrm{p}-\mathrm{GaN}$ and $\mathrm{p}-\mathrm{Al}_{0.1} \mathrm{Ga}_{0.9} \mathrm{~N} / \mathrm{GaN}$ superlattices. Appl. Phys. Lett. 2001, 79, 3636-3638. [CrossRef]

52. Logan, R.A.; Thurmond, C.D. Heteroepitaxial thermal gradient solution growth of GaN. J. Electrochem. Soc. 1972, 119, 1727-1735. [CrossRef]

(C) 2019 by the authors. Licensee MDPI, Basel, Switzerland. This article is an open access article distributed under the terms and conditions of the Creative Commons Attribution (CC BY) license (http://creativecommons.org/licenses/by/4.0/). 